\title{
COVID-19 Vaccine Acceptability: A Cross-Sectional Mixed Methods Study in Sierra Leone
}

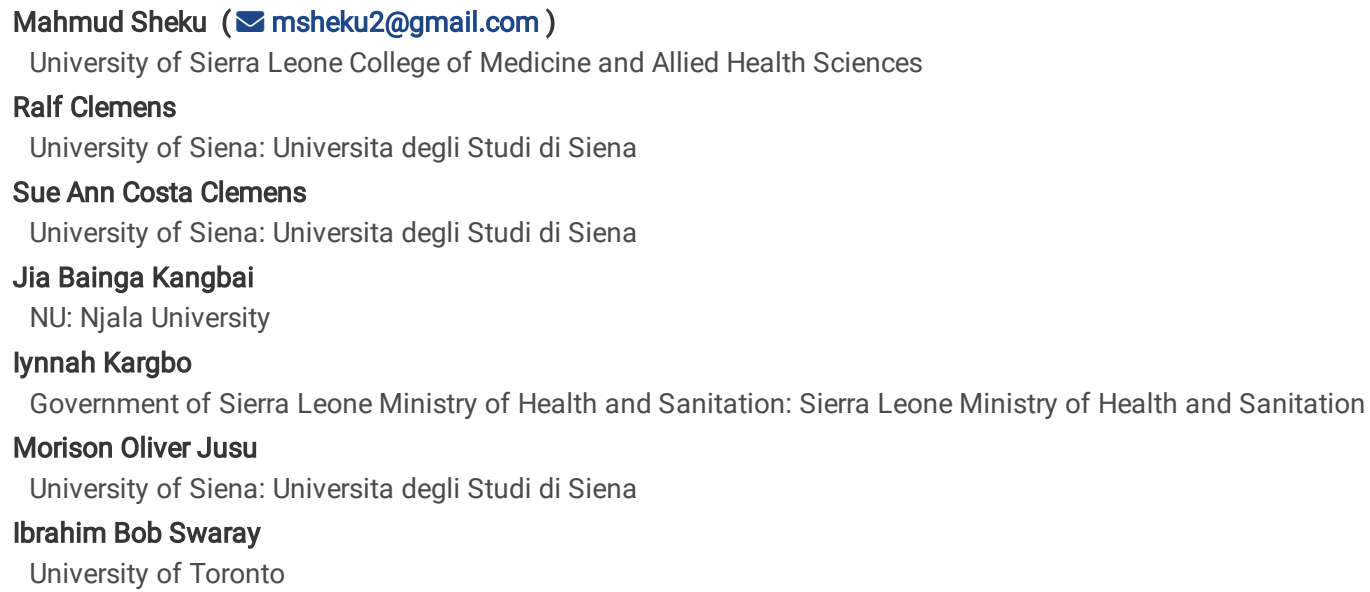




\section{Abstract}

Background: Global immunization is critical to combat the COVID-19 pandemic and the public's willingness to be vaccinated will determine the success of elimination efforts. We measured the acceptability of COVID-19 vaccine and views in Sierra Leone.

Method: We used a multi-method study including an online cross-sectional survey and semi-structured interviews to assess the acceptance of and perceptions about COVID-19 vaccination among 2146 Sierra Leoneans aged 18 years and above.

Results: Most survey respondents $(80.1 \%, n=1719)$ would accept COVID-19 vaccination for themselves and close family,but $19.9 \%(n=427)$ would reject vaccination. If vaccination was mandatory the acceptance rate would increase to $85.0 \%$, $(n=1,823)$, while $15.0 \%$ ( $n=318)$ of responders would still reject. COVID-19 vaccine awareness was high among respondents (yes: $75.2 \% n=1613, n o: 24.8 \%, n=533$ ). Safety, immunity, and trust in vaccines were the main reasons for vaccine acceptance. Distrust, uncertainties about vaccine safety and effectivenessand lack of belief in the COVID-19 pandemic triggered through media reports were the mainreasons for rejecting the COVID-19 vaccination. With respect to vaccine,a small majority would prefer a less reactogenic vaccine even at the cost of a lower efficacy over a more effective but more reactogenic vaccine $(55.7 \%, n=1195$ vs $41.5 \%, n=890)$ while2.8\% $(n=61)$ of respondents said they would reject any vaccine.Country of origin had an important role in vaccine acceptance: $32.4 \%(n=1121)$ would accept a vaccine from any country if licensed locally, but15.1\%( $n=511)$ would rejectvaccines even if licensed from China,12.6\% $(n=437)$, India 11.4\% ( $n=393)$, USA 8.0\% ( $n=276)$, Germany7.8\% ( $n=271)$, Russia 7.7\% ( $n=267)$, UKand 5.0\% ( $n=173)$ from Belgium.

Conclusion: Sensitizing the public about the COVID-19 infection risk, vaccine development processesand ensuring vaccine safety through continuous communication and community engagement, with community leaders leading by example as well as the independent role of regulatory authorities in safety and efficacy evaluation, would improve COVID-19 vaccine acceptance.

\section{Background}

The world is struggling to deal with the unparalleled strain of morbidity and mortality incurred by the COVID-19 pandemic as populations and economies are severely disrupted. As of May 18th, 2021, nearly 164.7 million confirmed cases of SARS-CoV-2 infection (COVID-19) have been reported globally, with more than 3.4 million reported deaths. Of these, Sierra Leone has recorded around 4,107 cases $(6.4 \%$ of which are among health workers) and 79 deaths, giving a case fatality rate (CFR) of $2.0 \%$, which is higher than most countries severely affected [1-4].

Various public health interventions, including banning travel, imposition of social distancing and curfews, have been proposed to stop the transmission of the disease. However, the most promising control strategy is through large-scale, equitable access and distribution of safe and effective COVID-19 vaccines. There are thirteen vaccines already approved or with emergency use authorization, all of which meet the WHO criteria for efficacy of $50 \%$-point estimate and minimum $30 \%$ lower $\mathrm{IC}_{95}$ bound. The majority of those have a reported efficacy of $>65 \%$ [5-14]. Through the COVAX initiative various vaccine development partners (WHO, CEPI, BMGF, GAVI, the Wellcome Trust, and other government and non-governmental agencies), have outlined a mechanism for ensuring the availability of such COVID-19 vaccines.

In Sierra Leone, the government and other organizations are coordinating programs to ensure that COVID-19 vaccines are accessible to the public. The success of any COVID-19 vaccine program will depend on the public's desire and readiness to accept these and other vaccines. Meanwhile, vaccine hesitancy attributable to multiple causes appears to be a threat that could theoretically affect attempts to control the pandemic through vaccination and immunization [15-19]. In March 2021 A professional polling unit (SierraPoll) at the Institute for Governance Reform reported that a 3-day poll showed COVID-19 vaccine acceptance in the capital city of Sierra Leone, Freetown, was as low as $43.0 \%$ [20].

Several other countries have surveyed the level of COVID-19 vaccine acceptability, with mixed levels of acceptance reported. These have been largely linked to the level of perceived risk from SARS-CoV-2, the degree of trust in COVID-19 vaccine research, and the efficacy and duration of protection conferred by the vaccine $[17,19]$. Studies conducted in South Africa, Indonesia, Uganda, and the Côte d'Ivoire reported COVID-19 acceptance rates between $51.0 \%$ and $69.0 \%$, while others in Kenya, Nigeria, and Mozambique all reported 68\% acceptance [16, 21-25]. In Brazil, South Korea, Mexico, USA, India, UK, Italy, and France reported acceptance rates range from a high of $85 \%$ in Brazil to a low of $59 \%$ in France $[19,26-29]$.

Survey data from multiple sources suggest an overall 60-70\% willingness to be vaccinated with a novel COVID-19 vaccine with significantly lower rates decline among Black or Hispanic communities, people with lower educational level, and those living in rural areas $[16,19]$.

As of May $18^{\text {th }}$, 2021, there have been 1.51 billion doses of vaccine administered in 176 countries [30]. In Sierra Leone of the 296,000 doses of AstraZeneca COVID-19 vaccine received through the COVAX initiative) only 64,966 doses ( $0.73 \%$ of people vaccinated) have been administered together with 96,000 doses of 200,000 doses available from SinoPharm COVID-19 vaccine from China. The COVID-19 pandemic has also impacted Sierra Leone vaccination rates in general, with a $19 \%$ decline in infant vaccination coverage less than five months into the COVID-19 era [29].

Recognizing that most of the population may be eligible for the COVID-19 vaccine, we performed a multi-method study to assess the views and perceptions of Sierra Leoneans regarding the acceptability of the COVID-19 vaccine, both for themselves and for their children or relatives. This cross-sectional mixedmethods study attempts to quantify COVID-19 vaccine acceptability and views across the country. It is hoped that the findings from this study will be used to guide the COVID-19 vaccine deployment process in Sierra Leone.

\section{Methods}


We used a cross-sectional web questionnaire to assess Sierra Leoneans in four regions for their views and beliefs on vaccinations. We used a qualitative and quantitative approach to gain a detailed understanding of the acceptability.

The survey was established by the researchers in consultation with the immunization officials from the Sierra Leone Expanded Programme on Immunization (EPI). In refining the survey questions and structure, we received input from Sierra Leoneans aged 18 years and above on the comprehensibility, accessibility and time taken to complete the survey from the point of view of the target audience.

Between February 22, 2021 and March 25, 2021, we recruited resident Sierra Leoneans aged 18 years and over from the 16 districts (Urban: 548; Rural: 1,598) to take part in the survey. We recruited and trained twelve college students to work as research assistants, whose main responsibilities were to coordinate and administer the survey questionnaires to prospective participants to meet the districts' recruitment targets. The hyperlink to the survey information and the questionnaire was sent to these research assistants for participant recruitment. Using both social media (WhatsApp) and face-to-face approaches to recruitment, the research assistant in each district randomly identified qualified participants through WhatsApp groups or direct contact and shared the full study detail with them, including study purpose, informed consent, and their ability to withdraw from the survey, as well as concerns related to confidentiality and data security. The research assistant then sent the link to the survey questionnaire to those who had expressed an interest in participating and as well administering the questionnaire to those who did not have an Android phone. The importance of written informed consent was stressed in all research materials, and it was made clear that only the data collected by participants who completed the whole survey would be analyzed.

The questionnaire (see Appendix) cover3e demographics and COVID-19 vaccine-related questions. The opening part of the questionnaire consist3e of questions related to participants' demographic information, including region, gender, age, employment status, household income, and level of education. The research part of the questions explored COVID-19 vaccine awareness, acceptability to be vaccinated, and the participant's views relating to COVID-19 vaccine. A 4-point Likert scale was used to ensure that participants made choices. Multiple checkboxes were used for participants to illustrate their answers to the two questions about the acceptability of the vaccine for themselves and their children/relatives. Two open-ended questions were administered to a randomly selected $2.5 \%$ participants of the total respondents to further explore reasons for COVID-19 vaccine acceptability or rejection.

STATA v15 was used to clean and analyze the quantitative data and the aggregate results were presented in frequencies, percentages, means and standard deviations and summarized in tables and graphs. The qualitative data was analyzed thematically in Microsoft Excel.

A paired samples t-test with $a=0.05$ was used to assess COVID-19 vaccine acceptance for self and children/relatives. The demographic variables correlated with COVID-19 vaccine acceptance for both self and children/relatives were then assessed using two logistic regression analyses. In logistic regression models, the variables region, age, daily household income, employment, education, and healthcare worker were used as predictors.

The open-text responses were thematically analyzed in Microsoft Excel, and the coding schemes were developed based on the open-text comments.

All questionnaires were assigned a serial number, which was captured as each participant's ID.

\section{Results}

We approached 2570 individuals aged 18 years and recruited a total of 2201 (85.6\%) to participate in the survey of whom 2146 respondents (Urban: 548 ; Rural: 1,598) were included in the final analyses as 55 respondents had to be excluded due to missing data. Of the 2146 analyzed (Table 1$), 1286$ (59.9\%) were male, most were educated up to high school level $(n=1208 ; 52.3 \%)$ and $344(16.0 \%)$ were classified as employed. Ages ranged from 18 to $65+$ years (Median $=25-54$ years). The median daily household income reported was $<\$ 2$. Of the total participants, we randomly identified $5 \%(n=110)$ for a follow up interview, of whom $63(57.3 \%)$ accepted to be interviewed (male $=38$, female $=25)$ and $47(42.7 \%)$ did not respond to calls by the study team or declined to be interviewed. Demographics of this subset were similar to the overall study cohort.

Among the study participants $75.2 \%(n=1613)$ were aware that a COVID-19 vaccine was available, while $24.8 \%(n=533)$ were not aware.

Overall, $80.1 \%(n=1719)$ of respondents would accept a vaccine for themselves and close family, whereas $19.9 \%(n=427)$ reported rejecting a COVID-19 vaccine for themselves and their children/relatives. If vaccination was mandatory the acceptance rate increased slightly $(85.0 \%, n=1823)$ but $15.0 \%(n=318)$ of responders would still reject to be vaccinated (Table 2). There was no significant difference in COVID-19 vaccine acceptance for self and for relatives. 


\begin{tabular}{|c|c|}
\hline \multicolumn{2}{|l|}{ Table 1: Profile of survey respondents } \\
\hline Characteristics & Frequency (\%) \\
\hline \multicolumn{2}{|l|}{ Region } \\
\hline East & $546(25.4 \%)$ \\
\hline North & $569(26.5 \%)$ \\
\hline South & $483(22.5 \%)$ \\
\hline West & $548(25.5 \%)$ \\
\hline Total & $2,146(100.0 \%)$ \\
\hline \multicolumn{2}{|l|}{ Gender } \\
\hline Female & $860(40.1 \%)$ \\
\hline Male & $1,286(59.9 \%)$ \\
\hline \multicolumn{2}{|l|}{ Age } \\
\hline 18-24 years & $338(15.8 \%)$ \\
\hline $25-54$ years & $1,068(49.8 \%)$ \\
\hline $55-64$ years & $498(23.2 \%)$ \\
\hline $65+$ years & $242(11.3 \%)$ \\
\hline \multicolumn{2}{|l|}{ Healthcare or COVID-19 frontline worker? } \\
\hline No & $1,837(85.6 \%)$ \\
\hline Yes & $309(14.4 \%)$ \\
\hline \multicolumn{2}{|l|}{ Level of Education } \\
\hline Master's or Ph.D. & $65(3.0 \%)$ \\
\hline BSc/Undergraduate & $329(15.3 \%)$ \\
\hline High school or some college (e.g., Diploma) & $814(37.9 \%)$ \\
\hline No school or less than high school & $938(43.7 \%)$ \\
\hline \multicolumn{2}{|l|}{ Employment status } \\
\hline Employed_full time & $344(16.0 \%)$ \\
\hline Self-employed & $895(41.7 \%)$ \\
\hline Student & $495(23.1 \%)$ \\
\hline Unemployed & $412(19.2 \%)$ \\
\hline \multicolumn{2}{|l|}{ Household Income Per Day? } \\
\hline$<\$ 2$ & $1,367(63.7 \%)$ \\
\hline$\$ 2-\$ 4$ & $453(21.1 \%)$ \\
\hline$\$ 4.1-\$ 8$ & $228(10.6 \%)$ \\
\hline$\$ 8.1+$ & $98(4.6 \%)$ \\
\hline
\end{tabular}




\begin{tabular}{|c|c|}
\hline \multicolumn{2}{|l|}{ Table 2: Details of COVID-19 Vaccine Acceptance } \\
\hline COVID-19 Vaccine Acceptance Questions & Frequency (\%) \\
\hline \multicolumn{2}{|l|}{ COVID-19 vaccine opinions for self and for relatives } \\
\hline Full acceptance & $1,648(76.8 \%)$ \\
\hline Partial Acceptance & $71(3.3 \%)$ \\
\hline Full Rejection & $427(19.9 \%)$ \\
\hline Total & $2,146(100.0 \%)$ \\
\hline \multicolumn{2}{|l|}{ Will you Accept the COVID-19 vaccine for yourself? } \\
\hline Yes, definitely & $1,489(69.4 \%)$ \\
\hline Unsure but leaning towards yes & $215(10.0 \%)$ \\
\hline No, definitely not & $393(18.3 \%)$ \\
\hline Unsure but leaning towards no & $49(2.3 \%)$ \\
\hline \multicolumn{2}{|c|}{ Will you accept the COVID-19 vaccine for your close relatives, including your children? } \\
\hline Yes, definitely & $1,431(66.7 \%)$ \\
\hline Unsure but leaning towards yes & $232(10.8 \%)$ \\
\hline No, definitely not & $385(17.9 \%)$ \\
\hline Unsure but leaning towards no & $98(4.6 \%)$ \\
\hline \multicolumn{2}{|c|}{ Will you accept the COVID-19 vaccine if recommended by law or employer? } \\
\hline Yes, definitely & $1,823(84 \%)$ \\
\hline No, definitely not & $318(14.8 \%)$ \\
\hline No response & $5(0.2 \%)$ \\
\hline \multicolumn{2}{|l|}{ What vaccine profile would you prefer? } \\
\hline A vaccine with higher efficacy but also higher adverse events & $890(41.5 \%)$ \\
\hline A vaccine with lower efficacy but also less adverse events & $1,195(55.7 \%)$ \\
\hline None & $61(2.8 \%)$ \\
\hline \multicolumn{2}{|l|}{ Are you aware of the availability of the COVID-19 vaccine? } \\
\hline Yes & $1613(75.2 \%)$ \\
\hline No & $531(24.7 \%)$ \\
\hline No response & $2(0.1 \%)$ \\
\hline
\end{tabular}

Of the $1,719(80.1 \%)$ respondents that would accept a COVID-19 vaccine for themselves or their relatives, 1,641 (95.5\%) gave reasons for their motivation to accept the COVID-19 vaccination. In order of frequency, the survey participants reported the following reasons for accepting COVID-19 vaccination for themselves and their relatives (Fig. 1).

The most frequent reason reported for accepting COVID-19 vaccination was that COVID-19 vaccination ensures that the person vaccinated stay safe (25.0\%, $\mathrm{n}$ $=871$ ). For $16.0 \%$, recommendation by leaders were important, and $5 \%$ would switch their attitude from non-acceptance to acceptance if it was mandatory.

Survey participants and interviewees cited less risk to infection for themselves and their relatives when they are vaccinated. $11.0 \%(n=393)$ respondents reported that they and their relatives are at less risk to COVID-19 if they are vaccinated while $9.0 \%(n=299)$ reported that they are in an at-risk group or close to someone that is at high risk to infection. The protection from COVID-19 infection of both the vaccinaees and others through immunization was reported as one of the major reasons for accepting COVID-19 vaccination. Respondents cited that COVID-19 vaccination protect those vaccinated and others (8.0\%, $\mathrm{n}=$ 292).

Of the 427 (19.9\%) respondents who rejected receiving COVID-19 vaccine, 318 (15.0\%) said they would refuse even if vaccination was mandatory; their reasons to reject are shown in Fig. 2. The main reason for rejection was lack of trust $(38.0 \%, n=371)$ with respect to vaccines, the government, and the healthcare system. Many respondents also expressed concerns about vaccine safety and effectiveness $(19.0 \%, n=181)$ and vaccine components $(11.0 \%, n=$ 102). The main concerns were about the COVID-19 vaccine research, the process, and the data generated to support the approval, while others said they did not believe in the benefit of the vaccines because of what they had seen in the media. 
These concerns were also propagated in some of the oral interviews by some interviewees who expressed "anti-vaxxer" opinions and doubted scientific expertise. Linked to this the lack of adequate information on COVID-19 and vaccine was stated the fourth main reason for rejecting COVID-19 vaccine (10.0\%, $n=95)$. Another reason, expressed by $9.0 \%(n=71)$ of those who reject vaccination was that they believe that COVID-19 is not real in Sierra Leone or in Africa, but it is "fake news". Some respondents mentioned that they and their relatives are not in an at-risk group $(5.0 \%, n=48)$ or are at low risk of getting infected or spreading COVID-19 $(5.0 \%, n=44)$ and hence they would refuse vaccination.

We ran a forward stepwise logistic regression analysis with the discrete variable being the self-COVID-19 vaccine acceptance variable. The predictive variables were region, age, gender, education, employment, daily household income, and healthcare worker. All but gender and education were predictive (Table 3 ) of COVID-19 vaccine rejection for self (Chi-square $=37.15, \mathrm{df}=12, \mathrm{p}=0.001$ ). The goodness-of-fit test (Hosmer-Lemeshow) proves that the model is well-suited to the data (Chi-square $=8.58, \mathrm{df}=12, \mathrm{p}=0.379$ ).

\begin{tabular}{|c|c|c|c|c|c|c|}
\hline \multirow[t]{2}{*}{ Variable } & \multicolumn{3}{|c|}{ Univariable Analysis } & \multicolumn{3}{|c|}{ Multivariable Analysis } \\
\hline & P-value & OR & $95 \% \mathrm{CL}$ & P-value & OR & $95 \% \mathrm{CL}$ \\
\hline Region & 0.000 & - & - & 0.043 & - & - \\
\hline East $(n=546)$ & - & - & - & - & - & \\
\hline West $(n=548)$ & 0.000 & 0.299 & $0.216-0.414$ & & & \\
\hline North $(n=569)$ & 0.000 & 0.285 & $0.206-0.393$ & & & \\
\hline South $(n=483)$ & 0.741 & 1.069 & $0.719-1.590$ & & & \\
\hline Age & 0.000 & - & - & 0.000 & - & - \\
\hline $18-24$ years $(n=338)$ & - & - & - & - & - & \\
\hline $25-54$ years $(n=1,068)$ & 0.034 & 1.349 & $1.022-1.780$ & 0.026 & 1.371 & $1.038-1.810$ \\
\hline $55-64$ years $(n=498)$ & 0.000 & 2.801 & $1.958-4.005$ & 0.000 & 3.024 & $2.096-4.361$ \\
\hline $65+$ years $(n=242)$ & 0.012 & 1.666 & $1.118-2.483$ & 0.003 & 1.880 & $1.239-2.853$ \\
\hline Employment Status & 0.000 & - & - & 0.000 & - & - \\
\hline Unemployed $(n=412)$ & - & - & - & - & - & - \\
\hline Student $(n=495)$ & 0.001 & 1.651 & $1.227-2.222$ & 0.000 & 2.135 & $1.551-2.938$ \\
\hline Self-employed ( $n=895)$ & 0.000 & 2.472 & $1.879-3.252$ & 0.000 & 2.300 & $1.718-3.079$ \\
\hline Employed full time $(n=344)$ & 0.000 & 2.207 & $1.559-3.123$ & 0.000 & 2.141 & $1.503-3.050$ \\
\hline Daily Household Income & 0.000 & - & - & 0.001 & - & - \\
\hline$<\$ 2(n=1,367)$ & - & - & - & - & - & - \\
\hline$\$ 2-\$ 4(n=453)$ & 0.002 & 0.673 & $0.523-0.864$ & 0.000 & 0.433 & $0.350-0.612$ \\
\hline$\$ 4.1-\$ 8(n=228)$ & 0.542 & 1.122 & $0.775-1.625$ & 0.008 & 0.507 & $0.356-0.857$ \\
\hline$\$ 8.1+(n=98)$ & 0.005 & 0.525 & $0.334-0.823$ & 0.000 & 0.206 & $0.157-0.443$ \\
\hline Healthcare/COVID-19 frontline worker & 0.000 & - & - & 0.001 & - & - \\
\hline No $(n=1,837)$ & - & - & - & - & - & - \\
\hline Yes $(n=309)$ & 0.000 & 2.487 & $1.697-3.644$ & 0.000 & 3.536 & $2.328-5.372$ \\
\hline
\end{tabular}

$\star \star$ Reference

Similar vaccine acceptance rates were observed in respondents who were over 24 years of age $(65+$ Years: OR $=1.88,95 \%$ Cl: $1.24-2.85,25-54$ Years: OR = $1.37,95 \% \mathrm{Cl}=1.04-1.81)$ with the exception of participants aged $55-64$ years $(\mathrm{OR}=3.02,95 \% \mathrm{Cl}$ : $2.10-4.36)$ who were three times more likely to accept a COVID-19 vaccine. With respect to employment status participants who reported being self-employed or in full-time employment were twice as likely to accept COVID-19 vaccination than those who were unemployed $(\mathrm{OR}=2.30,95 \% \mathrm{Cl}: 1.72-3.08)$.

There was no significant difference in vaccine acceptance across different income levels $(\$ 4.1-\$ 8: \mathrm{OR}=0.51,95 \% \mathrm{Cl}: 0.36-0.867 ; \$ 2-\$ 4: 0 R=0.43,95 \% \mathrm{Cl}$ : $0.35-0.61, \$ 8.1+: \mathrm{OR}=0.21,95 \% \mathrm{Cl}=0.16-0.44)$ and regions. Participants who self-reported as healthcare/frontline staff were three times more likely (OR: $3.53,95 \% \mathrm{Cl}: 2.33-5.37)$ than non-healthcare workers to accept COVID-19 vaccine.

We did the same analysis on the factors which would influence a participant to make recommendations for or against COVID-19 vaccination or relatives. There was no material difference between self-acceptance and recommendation for relatives for all the variables. 
Vaccine acceptance rates for relatives were similar in respondents above 24 years $(55-64$ years: OR $=3.31,95 \% \mathrm{Cl}: 2.20-4.98 ; 65+$ years: $\mathrm{OR}=1.97,95 \% \mathrm{Cl}$ : $1.25-3.13,25-54$ Years: $\mathrm{OR}=1.30,95 \% \mathrm{Cl}=0.96-1.76)$ compared with those aged 24 years or younger.

We had the same observations for participants who reported that they were self-employed or in full-time employment and students. Participants who reported being self-employed or students were twice as likely to accept COVID-19 vaccination than those who were unemployed (self-employed: OR $=2.88,95 \%$ Cl: 2.14-3.88; students: OR = 2.39, 95\% Cl: 1.73-3.29). Healthcare/frontline staff were three times more likely than non-healthcare workers to accept a COVID-19 vaccine for their relatives (OR: $3.45,95 \% \mathrm{Cl}: 2.33-5.13$; Table 4).

Table 4

Factors associated with COVID-19 vaccine acceptance for relatives

\begin{tabular}{|c|c|c|c|c|c|c|}
\hline \multirow[t]{2}{*}{ Variable } & \multicolumn{3}{|c|}{ Univariable Analysis } & \multicolumn{3}{|c|}{ Multivariable Analysis } \\
\hline & p-value & OR & $95 \% \mathrm{CL}$ & p-value & OR & $95 \% \mathrm{CL}$ \\
\hline Region & 0.000 & - & - & 0.033 & - & - \\
\hline East $(n=546) * *$ & - & - & - & - & - & \\
\hline West $(n=548)$ & 0.000 & 0.253 & $0.184-0.348$ & & & \\
\hline North $(n=569)$ & 0.000 & 0.275 & $0.200-0.377$ & & & \\
\hline South $(n=483)$ & 0.904 & 0.977 & $0.665-1.434$ & & & \\
\hline Age & 0.000 & - & - & 0.000 & - & - \\
\hline $18-24$ years $(n=338) * *$ & - & - & - & - & - & - \\
\hline $25-54$ years $(n=1,068)$ & 0.226 & 1.184 & $0.901-1.555$ & 0.186 & 1.300 & $0.957-1.764$ \\
\hline $55-64$ years $(n=498)$ & 0.000 & 2.634 & $1.856-3.739$ & 0.000 & 3.309 & $2.198-4.982$ \\
\hline $65+$ years $(n=242)$ & 0.021 & 1.585 & $1-071-2.347$ & 0.005 & 1.193 & $1.246-3.125$ \\
\hline Employment Status & 0.000 & - & - & 0.000 & - & - \\
\hline Unemployed $(n=412) * \star$ & - & - & - & - & - & - \\
\hline Student $(n=495)$ & 0.001 & 1.664 & $1.243-2.226$ & 0.000 & 2.390 & $1.733-3.294$ \\
\hline Self-employed $(n=895)$ & 0.000 & 2.375 & $1.819-3.102$ & 0.000 & 2.881 & $2.141-3.876$ \\
\hline Employed full time $(n=344)$ & 0.000 & 1.993 & $1.429-2.779$ & 0.000 & 1.728 & $1.781-4.179$ \\
\hline Daily Household Income & 0.002 & - & - & 0.001 & - & - \\
\hline$<\$ 2(n=1,367) * \star$ & - & - & - & - & - & - \\
\hline$\$ 2-\$ 4(n=453)$ & 0.001 & 0.669 & $0.524-0.853$ & 0.000 & 0.448 & $0.341-0.591$ \\
\hline$\$ 4.1-\$ 8(n=228)$ & 0.915 & 1.019 & $0.719-1.445$ & 0.004 & 0.496 & $0.324-0.578$ \\
\hline$\$ 8.1+(n=98)$ & 0.010 & 0.557 & $0.357-0.869$ & 0.000 & 0.240 & $0.142-0.406$ \\
\hline Healthcare/COVID-19 frontline worker & 0.000 & - & - & 0.000 & - & - \\
\hline No $(n=1,837) * \star$ & - & - & - & - & - & - \\
\hline Yes $(n=309)$ & 0.000 & 2.357 & $1.645-3.377$ & 0.000 & 3.454 & $2.326-5.129$ \\
\hline
\end{tabular}

One question was whether the country of origin of a Covid-19 vaccine influenced the decision to accept it or not. Whilst $32.4 \%(n=1121)$ reported that they would accept a vaccine from any country involved in vaccine manufacturing if licensed locally (Fig. 3), there were rejections at different levels depending on the vaccine manufacturing origin despite local licensure: China: $15.1 \% n=511)$; India: $12.6 \%(n=437)$; USA: $11.4 \%(n=393)$; Germany: $8.0 \%$ ( $n=276)$; Russia: $7.8 \%(n=271)$; UK: $7.7 \%(n=267)$; and Belgium: $5.0 \%(n=173)$.

Another question centered around vaccine profile preferences. A vaccine which is less reactogenic at the costs of being also less effective was favored by $56.0 \%(n=1195)$ compared with $41.0 \%(n=890)$ who preferred a vaccine with higher efficacy but also higher reactogenicity, while $3.0 \%(n=61)$ of respondents said they would reject any of the vaccine profiles (Fig. 4).

\section{Discussion}

This is the first prospective population-based study in Sierra Leone and one of the few in Western Africa about the acceptance or rejection of Covid-19 vaccination. A previous small poll in Sierra Leone conducted in 504 respondents in Freetown, the capital city of Sierra Leone, in early March 2021 showed an acceptance of $43.0 \%$. However, this survey was regionally restricted, with a different methodology, and conducted within three (3) days of Sierra Leone COVID19 vaccine reception period. As high vaccination coverage is critical for herd immunity, information about reasons for hesitancy or rejection are important to address those early on in a program. 
In this prospective study a majority of participants (80.1\%) reported that they would accept a COVID-19 vaccine for themselves and their relatives. Making COVID-19 vaccination mandatory would increase adherence to vaccination by just another $5 \%$. It is questionable whether a $5 \%$ increase in vaccine coverage warrants a debate about mandatory interventions and a potential increase in sentiment against vaccines.

This acceptance rate of $80.1 \%$ for COVID-19 vaccine in our study is higher than in other African countries such as Côte d'Ivoire, Uganda, Indonesia, Kenya, Nigeria, Mozambique, and South Africa where the reported acceptance levels range from a high of $69 \%$ to a low of $51 \%$. This is also true for some countries in other regions such as the United States, India, United Kingdom, Italy and France that reported acceptance rates between $59-75 \%$.

In our study we found no difference in acceptance levels between Black and Hispanic populations, or due to educational level, or residence in urban or rural areas. Region, age, employment, daily income, and healthcare workers were the major predictors for vaccine acceptance. Self-employed and full-time employed participants were more likely to accept vaccine for themselves and their relatives as were participants aged 25 years and above. Healthcare and frontline workers were more likely to accept COVID-19 vaccine for themselves and their relatives. This could be linked to their level of awareness of current health situation and the risk to exposure due to their involvement in providing care at the different health facilities.

Other than using the proven safety and efficacy of the vaccines another important factor to improve vaccination acceptance is leadership by example. As such, recommendations by governmental and seeing their leaders being vaccinated will influence acceptance. Quote of a participant:

"If the leaders like the president and the first lady take it and they're not affected negatively, yes, I'll accept it".

When asked about different vaccine profiles there was no clear preference: a small majority of respondents (56\%) would opt for a vaccine with lower reactogenicity at the expense of lower efficacy whereas $41 \%$ others preferred a vaccine with higher efficacy even if somewhat more reactogenic. There were, however, preferences of country of origin of vaccines with the lowest rejection of vaccines from countries who traditionally produced WHO prequalified vaccines such as Belgium or the UK, whereas the rejection rates for vaccines from India or China were higher. It is therefore important to educate the population that any COVID-19 vaccine, independent of its origin, which has a WHO EUL has an assured high standard of quality, safety and efficacy.

The main reasons for vaccine rejection were safety concerns, distrust about the COVID-19 vaccine research and data, the accelerated development process as well as the varying and confusing information in the media. Some respondents denied the reality of COVID-19 in Sierra Leone and Africa based on social media reports. Two answers exemplify the above:

"I don't believe that COVID-19 is in Sierra Leone and I do not believe in the COVID-19 vaccine as they intend to use it to poison us. They are using the COVID-19 situation to get money from donors".

I am rejecting the vaccine for myself and my relatives because I don't trust that it is safe. Maybe it is a means of especially reducing the Africa's population.

The increase in vaccine acceptance from the $43.0 \%$ acceptance rate in the poll in Freetown to the $80.1 \%$ acceptance in our study - although not directly comparable due to different methodologies - is remarkable. It indicates that there seems to be more trust based on science and dissemination of scientific facts and data.

Monitoring and reporting of safety signs should be at the core of the COVID-19 vaccine rollout activities, and it is critical for the government and health agencies to educate the public in an open and timely manner to avoid the new vaccines having a negative impact on the national immunization program. Importantly, leadership by example could have a big impact on acceptance. False information and fake news is also an issue in Sierra Leone and it is not always possible to overcome this with data. However, it is a minority who believe in this and it is questionable whether making vaccination mandatory would have a major benefit. Rather, the presence of these minorities makes it more important to achieve a high coverage in those who accept vaccination so that herd immunity can be established.

Our research has some limitations. A quantitative survey approach was amended by more qualitative interviews in a random subset to better understand rationales, feelings and emotions. However, because of the restriction during the OVID-19 pandemic this subset was limited in size. Our research took place at the height of the COVID-19 pandemic and during the evolution of the new variants spurring fear and inconsistency in COVID-19 information. Our recruiting approach obtained a high number of responses $(n=2146)$, but our sample is not reflective in terms of household income or educational level, despite being overwhelmingly representative regionally. There were some inconsistencies in responses which could not be verified, specifically a discrepancy between the answers around formal education and the reported daily income. Thus, our recording of household income is not strictly comparable to the Sierra Leone Demographic and Health Survey data (2019).

\section{Conclusions}

In this prospective survey $80.1 \%$ of the population of Sierra Leone had a favorable attitude towards COVID-19 vaccination. The primary reasons for their COVID-19 vaccination acceptance were to ensure personal and family safety and wellbeing. A key role in acceptance is the attitude of leaders. Denial of the COVID-19 reality, distrust in the COVID-19 vaccine research and vaccine safety as well as varying and false information in the media negatively influence vaccination acceptance. Sensitizing the public about the vaccine development process through continuous communication and community engagement, as well as the independent role of regulatory authorities in safety and efficacy evaluation, will be helpful in alleviating these concerns. Efforts should be made to clearly communicate COVID-19 risks, as well as to identify and resolve determinants of COVID-19 acceptance for all population segments

\section{Declarations}


Ethics approval and consent to participate

Ethical approval to conduct this study was granted by the Sierra Leone Ethics and Scientific Review Committee (Reference: 01 of 01 January 2021 ). All study procedures were performed in accordance with relevant guidelines and regulations. Informed consent to participate in the study was obtained from all subjects that participated in this study. This study presents no risk or harm to respondents.

\section{Consent for publication}

Not Applicable

\section{Availability of data and materials}

The full dataset is the property of the research team and are available from the corresponding author upon reasonable request and agreement.

\section{Competing interests}

The authors declare that they have no competing financial interests or personal relationships that might have arisen to influence the work published in this article.

\section{Funding}

Not Applicable

\section{Authors' contributions}

MS, RF, SAC, JBK, IK, MJ, and IBS designed and implemented the study. MS, RF, and SAC led the survey's design and developed the first draft of the manuscript. IK and IBS led survey and interview recruitments. MS and JBK performed the statistical analysis. MJ analyzed the qualitative interviews. All authors contributed to the manuscript preparation and approved the final manuscript.

\section{Acknowledgements}

We would like to thank the research assistants who helped to share the online survey with prospective participants. We are grateful for the time and contribution of all respondents who participated in the survey.

We would also like to thank the leadership of the Institute for Global Health, University of Siena, Italy, for all the knowledge and skills shared as part of the master's degree in vaccinology and drug development training program.

Finally, we would like to thank all research experts for their feedback on the design of the study, in particular the development of the survey tool and the final study content.

\section{References}

1. Coronavirus Updates. worldometer. 2020

2. WHO Coronavirus Disease (COVID-19) Dashboard I WHO Coronavirus Disease (COVID-19) Dashboard [Internet]. [cited 2021 Jan 2]. Available from: https://covid19. who.int/?gclid=CjOKCQiA0MD_BRCTARIsADXoopbpLu4StjMeRPiWOoPOn3KKN2iZon2JvYoPrbL7kOCP5pCoQY0o9z8aApJqEALw_wcB

3. European Centre for Disease Prevention and Control. COVID-19 situation updates worldwide, as of 29th September 2020. An Off EU website. 2020;2020(June):1-10

4. Ministry of Health and Sanitation. Corona Virus Disease (COVID-19) Situational Report - 035. Sierra Leone Minist Heal Sanit [Internet]. 2020;(035):1-3. Available from: https://ddc.moph.go.th/viralpneumonia/eng/index.php

5. COVID-19 vaccine tracker | RAPS [Internet]. [cited 2021 Apr 29]. Available from: https://www.raps.org/news-and-articles/news-articles/2020/3/covid-19vaccine-tracker

6. GAVI, the Vaccine Alliance [Internet]. [cited 2021 Jan 2]. Available from: https://www.gavi.org

7. COVAX [Internet]. [cited 2021 Jan 2]. Available from: https://www.who.int/initiatives/act-accelerator/covax

8. Policy Updates | Donor Tracker [Internet]. [cited 2021 Jan 2]. Available from: https://donortracker.org/policy-updates? field_countries_regions_topics_target_id_1\%5B18\%5D=18

9. Pfizer-BioNTech COVID-19 Vaccine | FDA [Internet]. [cited 2021 Jan 2]. Available from: https://www.fda.gov/emergency-preparedness-andresponse/coronavirus-disease-2019-covid-19/pfizer-biontech-covid-19-vaccine

10. Krause PR, Gruber MF. Emergency Use Authorization of Covid Vaccines - Safety and Efficacy Follow-up Considerations. N Engl J Med. 2020 Nov 5;383(19):e107

11. Covid-19: Oxford-AstraZeneca vaccine approved for use in UK - BBC News [Internet]. [cited 2021 Jan 2]. Available from: https://www.bbc.com/news/health-55280671

12. Coronavirus disease (COVID-19): Vaccines [Internet]. [cited 2021 Jan 2]. Available from: https://www.who.int/news-room/q-a-detail/coronavirus-disease(covid-19)-vaccines? 
adgroupsurvey=\%7Badgroupsurvey\%7D\&gclid=Cj0KCQiA0MD_BRCTARIsADXoopbcBkxPDma1VTPAZu9AgVgeha3GEJHbYjlcpyVawv74raa3ES_ooZUaAn

13. Pfizer Inc. Pfizer and BioNTech Announce Vaccine Candidate Against COVID-19 Achieved Success in First Interim Analysis from Phase 3 Study I Pfizer.

Pfizer [Internet]. 2020;1-3. Available from: https://www.pfizer.com/news/press-release/press-release-detail/pfizer-and-biontech-announce-vaccinecandidate-against

14. Latest: China approves use of Sinopharm's COVID-19 vaccine [Internet]. [cited 2021 Jan 2]. Available from:

https://www.nationalgeographic.com/science/health-and-human-body/human-diseases/coronavirus-vaccine-tracker-how-they-work-latest-developments$\mathrm{crd} /$

15. Reiter PL, Pennell ML, Katz ML. Acceptability of a COVID-19 vaccine among adults in the United States: How many people would get vaccinated? Vaccine. 2020 Sep 29;38(42):6500-7.

16. Echoru I. Acceptance and Risk Perception of COVID-19 Vaccine in Uganda: A Cross Sectional Study in Western Uganda. :1-11.

17. Acceptance A. 7 Achieving Acceptance of COVID- 19 Vaccine. 2020;

18. Boyon N. COVID-19 vaccination intent is decreasing globally. Ipsos [Internet]. 2020;1-6. Available from: https://www.ipsos.com/en/global-attitudes-covid19-vaccine-october-2020.

19. Malik AA, McFadden SAM, Elharake J, Omer SB. Determinants of COVID-19 vaccine acceptance in the US. EClinicalMedicine. $2020 ; 26$.

20. Westend CE, Freetown FF, Muslims C. QUESTIONS Do you know if there is COVID vaccine in $54.1 \%$ Freetown? Are you willing to Knowledge \& Attitudes Towards COVID Vaccine. 2021;(March):1-2.

21. Peretti-Watel P, Seror V, Cortaredona S, Launay O, Raude J, Verger P, et al. A future vaccination campaign against COVID-19 at risk of vaccine hesitancy and politicisation. Lancet Infect Dis. 2020;20(7):769-70.

22. Funk C, Tyson A. Intent to Get a COVID-19 Vaccine Rises to 60 \% as Confidence in Research and Development Process Increases. 2020;(December).

23. Africa S. Download Free Report ( https://knowledge.geopoll.com/cs/c/?cta_guid=b471350b-9319 Vaccine Hesitancy In Sub-Saharan Africa COVID-19 Vaccine Acceptance In South Africa , Kenya And More Conduct Research On Vaccines With GeoPoll. 2021;2020:11-3.

24. Ministry T. COVID-19 Vaccine Acceptance Survey in Indonesia. 2020;(November).

25. Jerving BS. 4 out of 5 Africans would take a COVID-19 vaccine: Africa CDC survey. 2020; 19:1-4.

26. Gadoth A, Halbrook M, Martin-Blais R, Gray AN, Tobin NH, Ferbas KG, et al. Assessment of COVID-19 vaccine acceptance among healthcare workers in Los Angeles. medRxiv [Internet]. 2020;(310). Available from: https://medrxiv.org/cgi/content/short/2020.11.18.20234468

27. Spotim-launcher-widget- $C$. Which parts of Europe are likely to be most hesitant about a COVID-19 vaccine? 2020;2(0).

28. Apple BA, Azimi T, Cordina J. COVID-19 vaccine: Are US consumers ready? 2020;1-16.

29. Bell S, Clarke R, Mounier-Jack S, Walker JL, Paterson P. Parents' and guardians' views on the acceptability of a future COVID-19 vaccine: A multi-methods study in England. Vaccine [Internet]. 2020;38(49):7789-98. Available from: https://doi.org/10.1016/j.vaccine.2020.10.027

30. More Than 1.51 Billion Shots Given: Covid-19 Vaccine Tracker [Internet]. [cited 2021 May 18]. Available from: https://www.bloomberg.com/graphics/covid-vaccine-tracker-global-distribution/

\section{Figures}

\section{Reasons for COVID-19 vaccine acceptance}

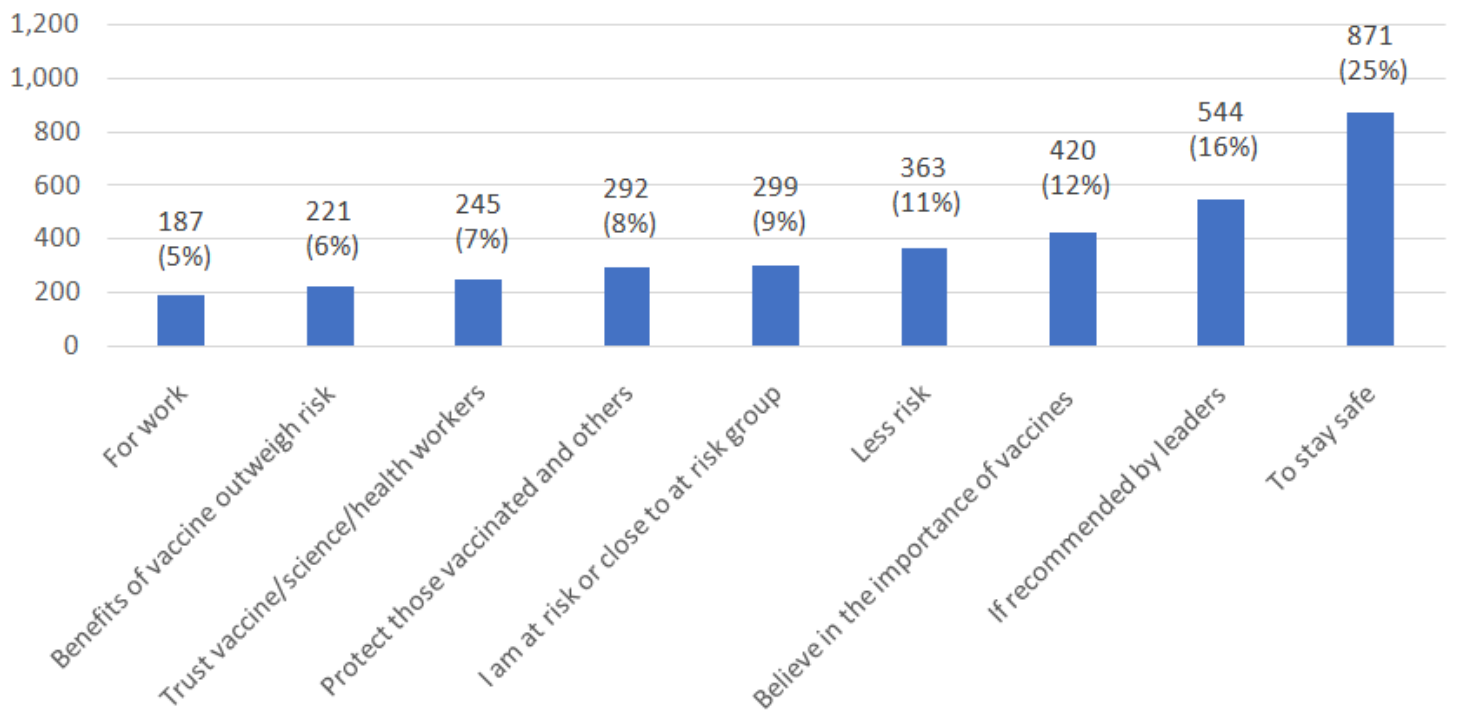

Figure 1

Main reasons for accepting COVID-19 vaccination 


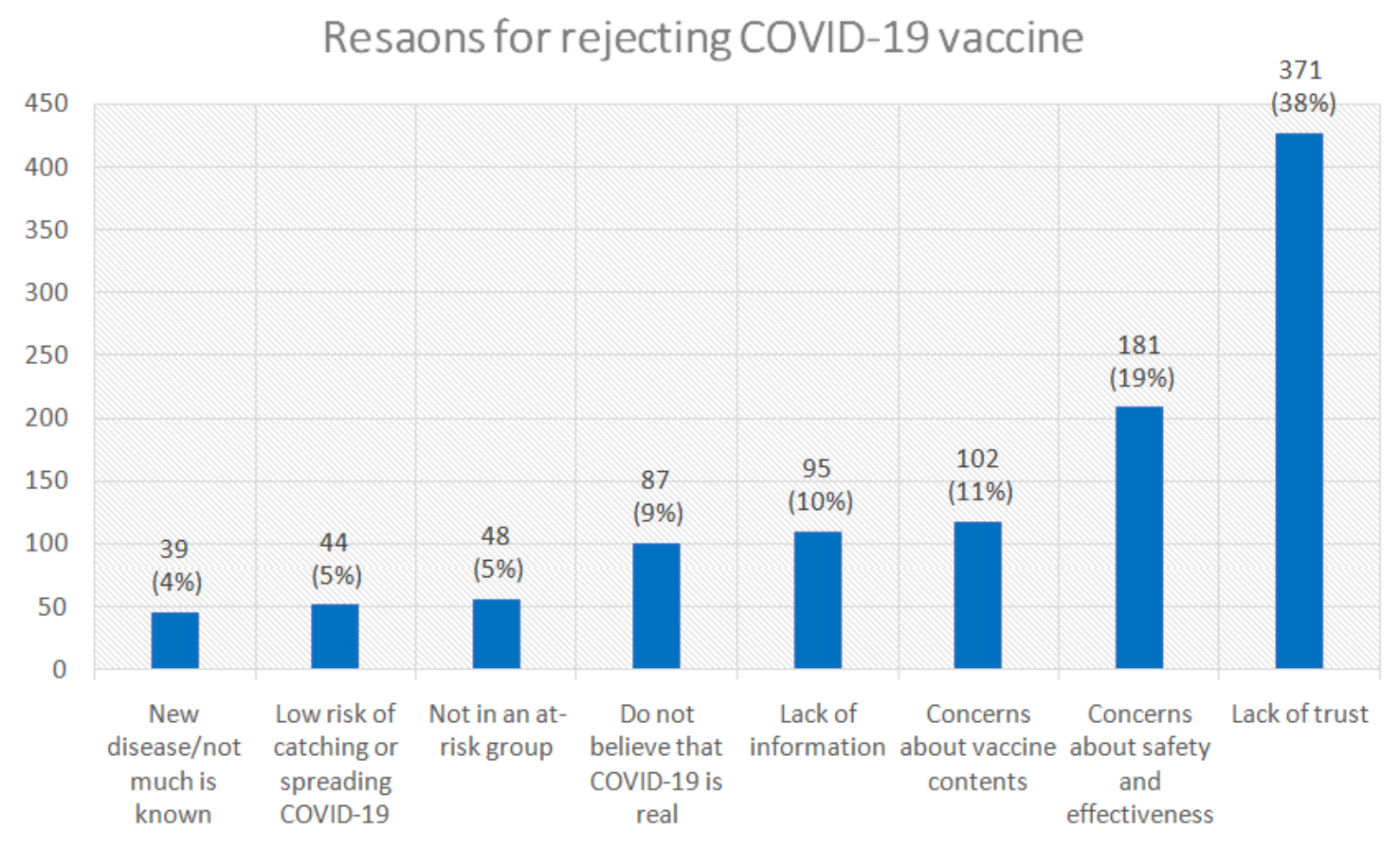

Figure 2

Main reasons for rejecting COVID-19 vaccination

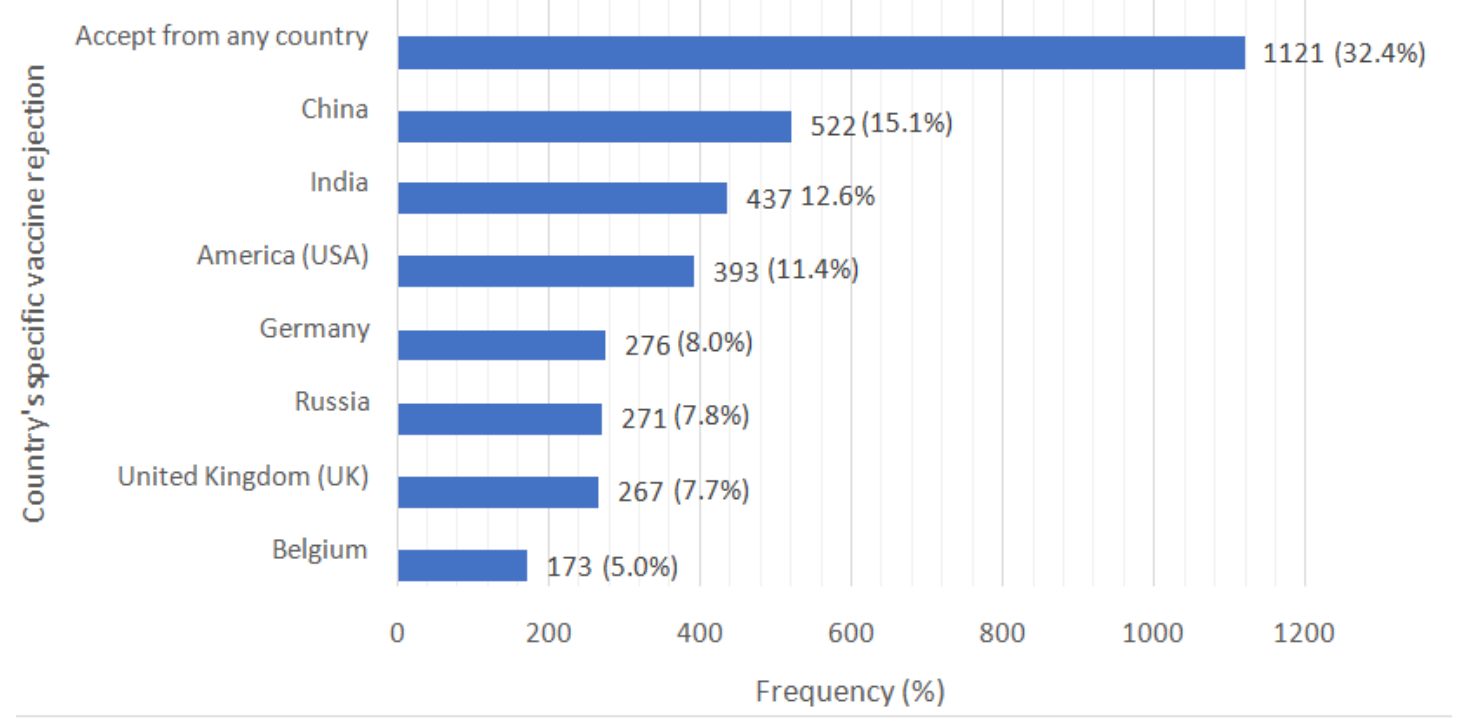

Figure 3

Country-specific vaccine rejection 


\section{Acceptance by vaccine profile}

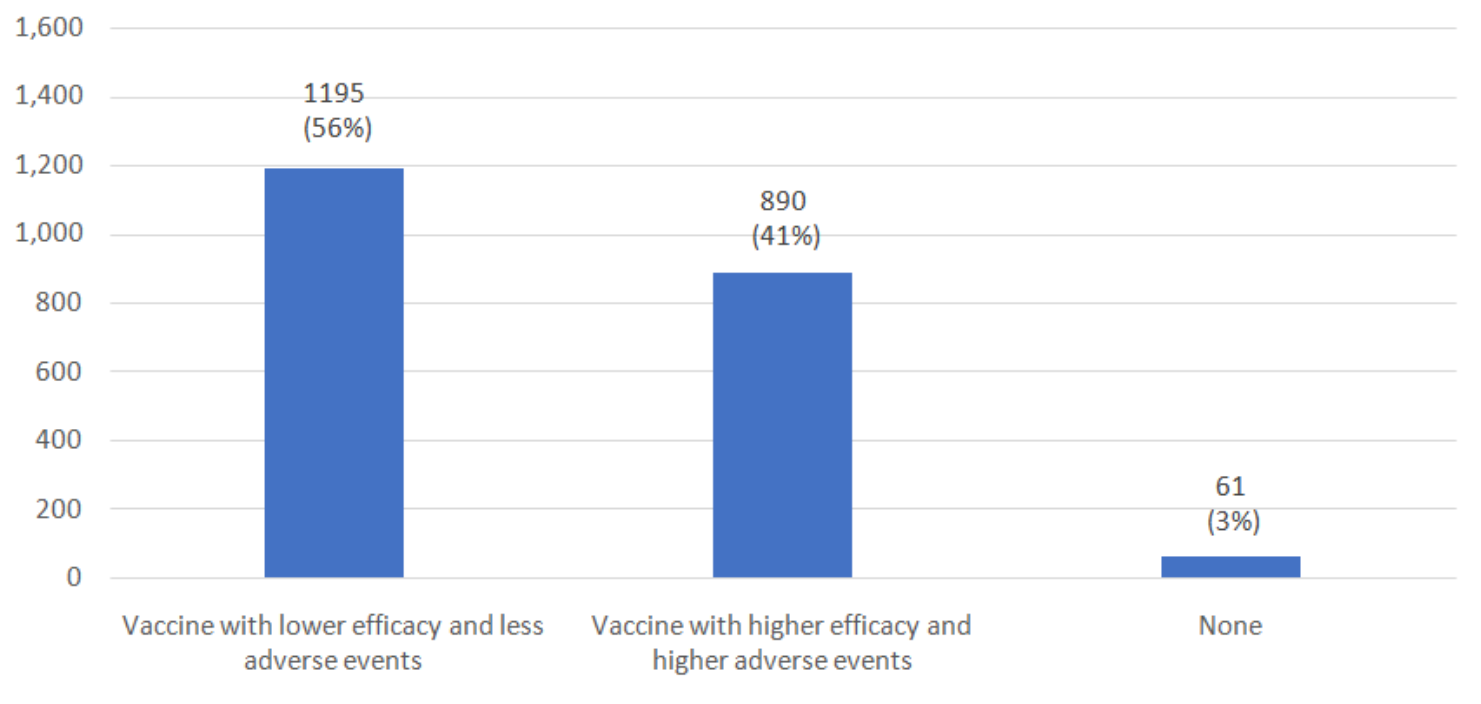

\section{Figure 4}

Acceptance by vaccine profile

\section{Supplementary Files}

This is a list of supplementary files associated with this preprint. Click to download.

- COVID19VaccineAcceptabilityandViewsAppendix.docx 